\title{
Finite Element Analysis of a Piston for a Disc Brake Master Cylinder
}

\author{
Sourabh M. Dhole ${ }^{+*}$, V. V. Saidpatil ${ }^{\ddagger}$ and S. Y. Gajjal ${ }^{\dagger}$ \\ †Mechanical Engg., NBN Sinhgad School of Engineering, Pune, Maharashtra, India \\ Accepted 01 Sept 2016, Available online 02 Sept 2016, Vol.6, No.5 (Oct 2016)
}

\begin{abstract}
Most of the two wheeler vehicles have disc brakes to their front wheel. The disc brake consists of master cylinder which is housing for a plunger which acts as a piston to create and push the pressurized oil into the oil hose of the front disc brake system. This piston is made of aluminum which is heavy in weight as compare to plastic. This project work focused on to change the material of the piston from aluminum to plastic so to reduce the piston weight. The locally manufactured aluminium piston was used for study purpose. To avoid measurement errors and to achieve close to accurate measurement of this piston, it was scanned and measured on machine. This scan data converted to CAD model and using FEA, stresses in Aluminum and Plastic has compared. The advantages of the changed material piston are the low cost and superior material properties. With above proposal we will get reduction in piston weight, design cost and productivity improvement due to material change of the piston from metal to plastic.
\end{abstract}

Keywords: master cylinder piston, material change, plastic material, design and optimization.

\section{Introduction}

The disc brake consists of master cylinder which is housing for a plunger which acts as a piston to create and push the pressurized oil into the oil hose of the front disc brake system. This piston is made of aluminum which is heavy in weight as compare to plastic. There is a possibility of scarcity of aluminium material; makes it costly and hence it is necessary to find more easily and abundantly available material. This project work focused on to change the material of the piston from aluminum to plastic.

This master cylinder piston is made up of aluminium which is heavy in weight as compare to plastic. The pistons which are used in hydraulic wheel cylinders and hydraulic master cylinders of the common hydraulic brake systems are made of aluminium and forming process consists of die casting the metal to give it the desired shape and then grinding the outer surface of the piston to obtain a piston diameter which will conform closely to the inner diameter of the cylinder in which the piston is to be used. While metals such as aluminium are satisfactory, proper combinations of non-metallic materials including some ceramics and filled hard plastic such as high glass content nylon are useful in some instances. The advantages of the changed material piston are the low cost and superior material properties. The conventional aluminium piston of the master cylinder is manufactured by the process of machining. This

*Corresponding author Sourabh M. Dhole is a PG student, V. V. Saidpatil is working as Associate Professor and S. Y. Gajjal as HOD piston manufactured by using plastic material through molding process and machining route.

(Schuller \& Eckstein, 2000) invented and manufactured a piston by using plastic material such as polytetrafluorethylene. The one end of the piston is called strike surface on which cam element exerts the linear forces. The wear resistant material such as metal like hardened steel or sintered ceramic is used as cam strike piece. This material is used as cam strike piece in disk shaped in between piston and strike surface to bear the stresses due to friction. The disk shaped cam strike piece is used as insert in the injection molding tool and plastic is injected around the insert except on the strike face. The piston is manufactured in one operation by using injection molding procedure which is simple, quick and cheap method. As the piston is manufactured by using plastic, it has the advantage of positive sliding property while sliding linearly in cylinder housing.

(Hauser M., et al.) to manufacture a master cylinder piston easily and at low price rate, inventors proposes a methodology that the piston includes a sleeve shaped part and a valve seat part made of plastic material and the valve seat part is press fitted into shaped part. This methodology allows a small and compact design of master cylinder. The other advantage of methodology that, it has minimum components that are manufactured from simple and low rate parts. They optimized the piston for its manufacturability while maintaining its functionality. 
Table 1 Polyphenylene Sulfide 40\% Glass Filled Material Properties

\begin{tabular}{|c|c|c|c|c|c|c|}
\hline Sr. No & Material & $\begin{array}{c}\text { Density } \\
\text { (tonnes } / \mathrm{mm}^{3} \text { ) }\end{array}$ & $\begin{array}{c}\text { Tensile } \\
\text { Modulus(MPa) }\end{array}$ & Poisson's Ratio & $\begin{array}{c}\text { Tensile Stress at } \\
\text { Break(MPa) }\end{array}$ & $\begin{array}{c}\text { Strain at } \\
\text { Break (\%) }\end{array}$ \\
\hline 1 & $\begin{array}{c}\text { FORTRON PPS } \\
\text { 1140L4 }\end{array}$ & $1.65 \mathrm{E}-09$ & 14700 & 0.38 & 195 & 1.9 \\
\hline
\end{tabular}

(Nakamura, 1985) manufactured a piston and master cylinder body from fiber glass nylon material as strengthened resinous material by molding operation which produces as single component as a result reduces weight and cost. The other objective of the invention is to produce a new and improved piston for a master cylinder which eliminates the previous disadvantages of piston. They found that, as the plug rests on the center of the concave surface of the piston, while manufacturing the piston by molding process, the flow of resinous material will improve and hence the dimensional accuracy of piston will be improved.

(Schard, 1982) manufactured the master cylinder piston as a composite assembly. This piston has an insert made of metallic, ceramic or high glass filled nylon plastic. The glass filled nylon plastic is molded around this insert to form a complete finished piston. The material of insert should be rigid enough and strong to transmit the longitudinal forces to which the piston is experienced without change in shape and wear through its lifetime.

(Genz \& Park , 1964) has following claims,

1) The piston assembly having two body members which have diameter less than the inside diameter of the cylinder. The body members formed a piston which reciprocates inside the cylinder. This movement of piston assembly increases the temperature of oil and piston assembly as well. To compensate the expansion of piston assembly, the materials used for piston body assembly have higher degree of thermal expansion than the cylinder material.

2) These body members have axial grooves on their surface to compensate an " $O$ " ring.

3) Overall, the piston assembly comprises of the packing rings on piston assembly body, compression washer and a threaded nut on piston rod for varying the body members' diameter and also the axial grooves on the surface. These body members are so formed that they can expand if temperature of oil or piston assembly increases.

The focus of this project is to change the material of the piston from aluminium to plastic. The plastic materials such as Nylon, PPS and other plastic materials are checked for its functionality and design for manufacturability. The plastic material was selected considering the main criteria's such as,

1) It should be chemically inert

2) It should be high temperature resistance

3) Hence it should maintain mechanical properties

4) It should be wear resistance

5) Have low cost and relevant characteristics.
Based on above criteria's, the Polyphenylene Sulfide (PPS) 40\% Glass Filled material have been selected. It has following properties shown in Table 1,

\section{For Boundary Conditions}

To carry out the analysis, the formation of cad model and its preprocessing is necessary. The boundary conditions in the form of Force require to stop the vehicle was calculated by the following procedure.

\section{Force Require to Stop Vehicle}

To calculate force required stopping the vehicle, we have considered 150cc two wheeler of mass $144 \mathrm{~kg}$ is travelling at $60 \mathrm{kmph}$. Determine 1) kinetic energy it possess. 2) The average braking force to bring it to rest in 30 meters.

Consider, KE = kinetic energy of vehicle

$$
\mathrm{M}=\text { mass of vehicle, } \mathrm{kg}
$$$$
\mathrm{U}=\text { speed of vehicle, } \mathrm{m} / \mathrm{s}
$$

The work done in bringing the vehicle to rest is given by

$$
\mathrm{WD}=\mathrm{FS}
$$

where, $\mathrm{WD}=$ work done, $\mathrm{J}$

$\mathrm{F}=$ average braking force, $\mathrm{N}$

$\mathrm{S}=$ distance travelled, $\mathrm{m}$

1) Speed of vehicle $U=60 \times 1000 / 60 \times 60$

$$
=16.67 \mathrm{~m} / \mathrm{sec} \text {. }
$$

2) Kinetic energy $=\frac{1}{2} M U^{2}$

$$
=\frac{1}{2} \times 144 \times(16.67)^{2}
$$

$\therefore$ Kinetic energy $=20008 \mathrm{~J}$

3) While braking a moving vehicle to a standstill, the work done by the brakes must equal the initial kinetic energy possessed by the vehicle so that

Work done to stop vehicle $=$ change in vehicle kinetic energy

$\therefore \mathrm{KE}=\mathrm{WD}$

$\therefore F S=\frac{1}{2} M U^{2}$

$\therefore 30 \mathrm{~F}=20008$

$\therefore \mathrm{F}=20008 / 30$

$\therefore \mathrm{F}=666.933 \mathrm{~N}$ 
After rounding off the figure and consider it as $670 \mathrm{~N}$, we use this value of force for applying the stress in CAE.

\section{Preprocessing}

\section{Cad Model Formation}

The locally manufactured existing aluminium piston was used for this work. This piston was scanned on machine and the raw cad model data saved in "stl" file format.

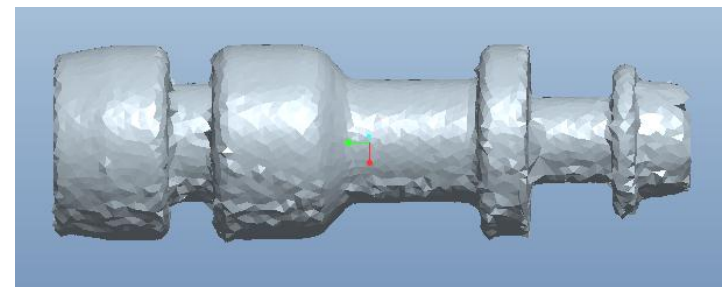

Fig. 1 Scanned Model of Piston

This file was then imported in Creo CAD software to remove rough edges or repair broken model.

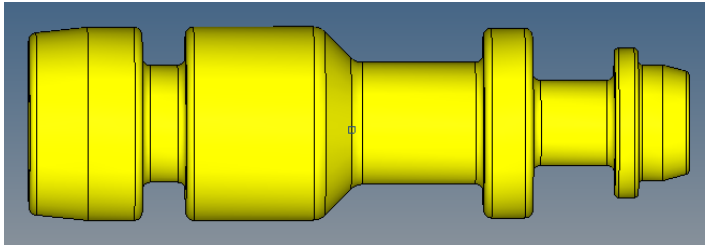

Fig. 2 Repaired CAD Model of Piston

\section{Meshing}

This repaired CAD model saved in "igs" file format and imported to Hypermesh software for preprocessing.

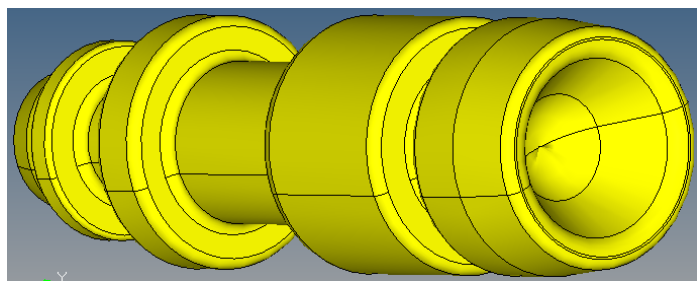

Fig. 3 CAD Model for Preprocessing

This model is preprocessed for geometry cleanup.

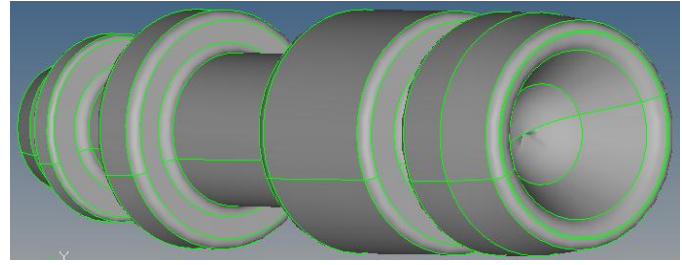

Fig. 4 CAD Model for Geometry Cleanup

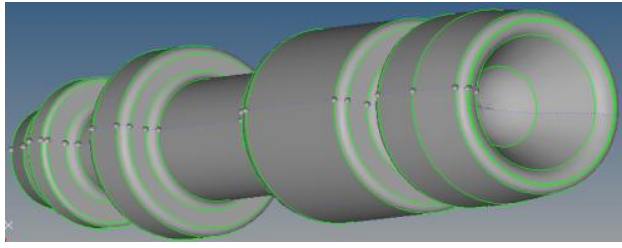

Fig. 5 Geometry Clean Cad Model

The above CAD model cleaned up for unnecessary lines and saved in ".hm" file format and then meshed.

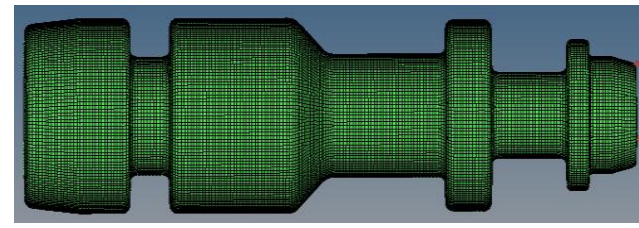

Fig. 6 Meshing of Piston

\section{Boundary Conditions for Stress Calculation}

This meshed model was analyzed in Abaqus for Non Linear analysis. The loading of $670 \mathrm{~N}$ was applied on the spring face and the lever face was constrained for all DOF.

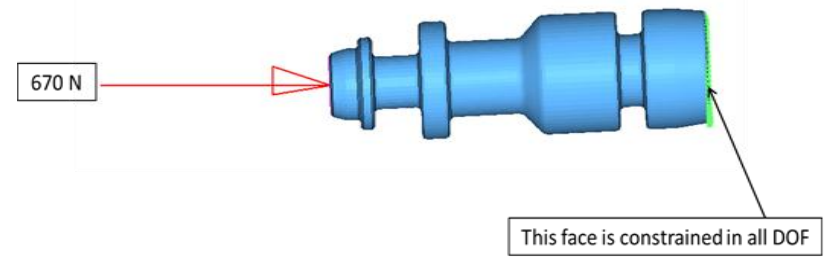

Fig. 7 Load Application on Piston

\section{Stress Calculation for Aluminium 6026}

As this piston was made in Aluminium, for analysis purpose, the material properties of Aluminium Alloy 6026 grade was considered. The corresponding properties are as shown in Table 2.

Table 2 Aluminium 6026 Material Properties

\begin{tabular}{|c|c|c|c|c|c|c|}
\hline $\begin{array}{l}0 \\
z \\
\dot{\omega}\end{array}$ & 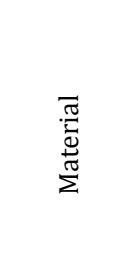 & 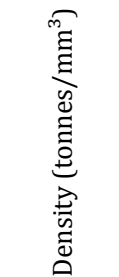 & 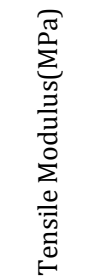 & 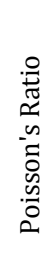 & 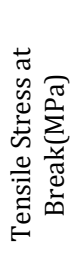 & 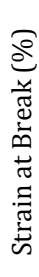 \\
\hline 1 & $\begin{array}{c}\text { Aluminum } \\
6026\end{array}$ & 2.72E-09 & 69000 & 0.3 & 360 & 4 \\
\hline
\end{tabular}

The analysis gives the following results for Force vs. Displacements in X, Y, Z axis as shown in Fig. 8 - 11, 


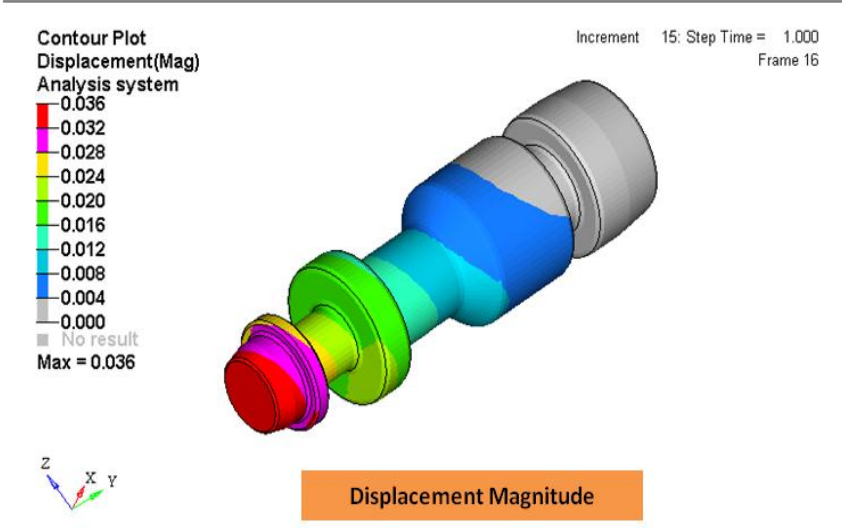

Fig. 8 Force vs. Displacement Magnitude

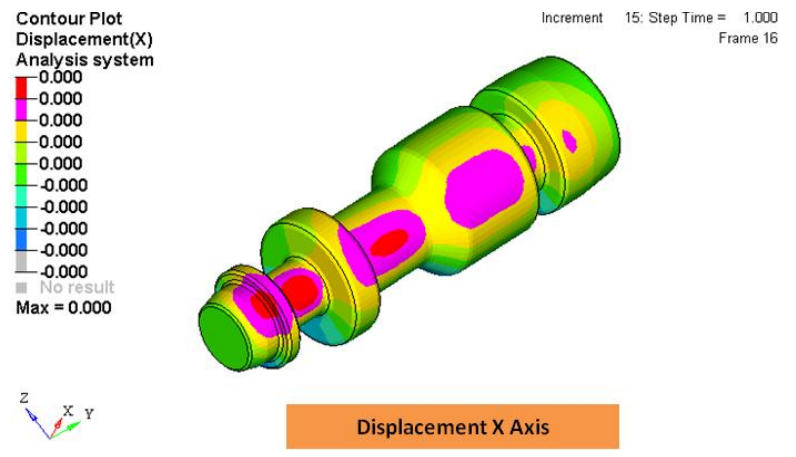

Fig. 9 Force vs. Displacement in X Axis

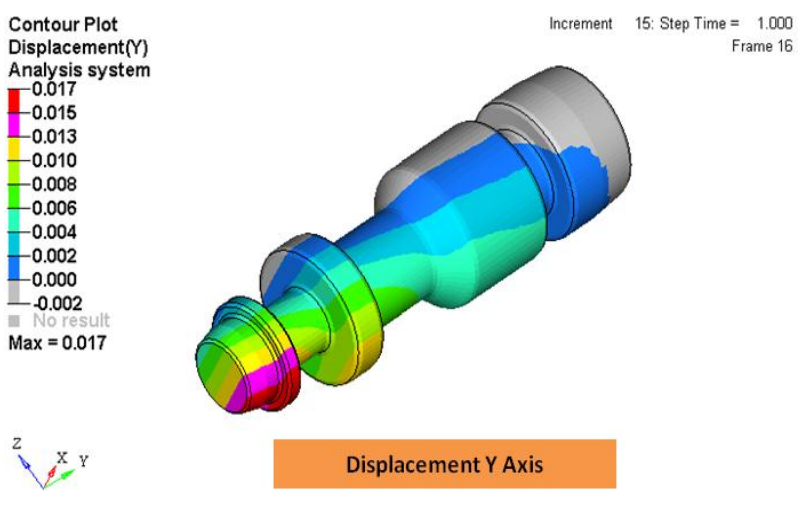

Fig. 10 Force vs. Displacement in Y Axis

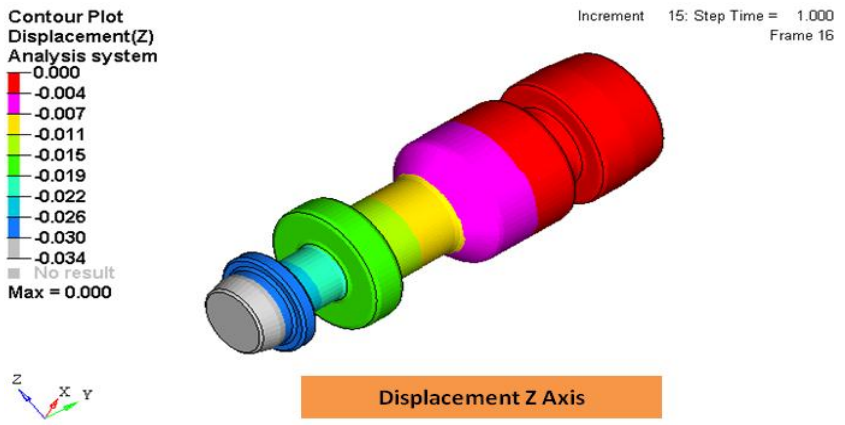

Fig. 11 Force vs. Displacement in Z Axis

For aluminium material, the stress-strain plots are as shown in Fig. 12, 13.

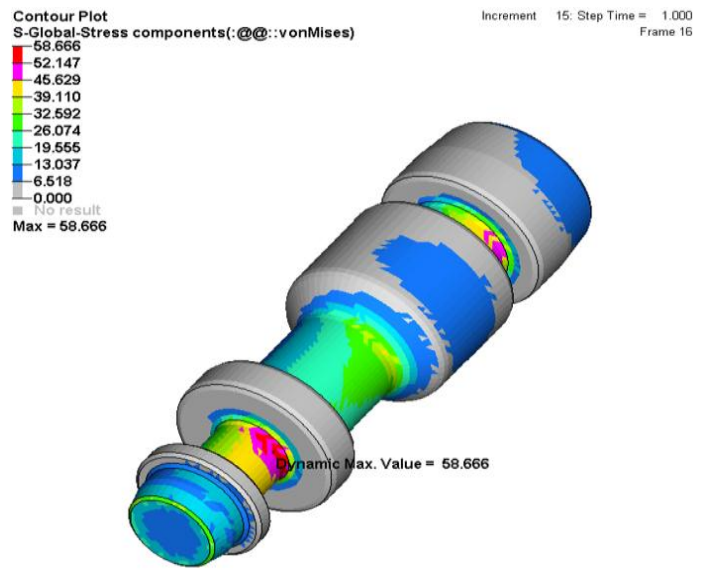

Aluminum 6026

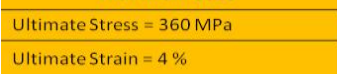

Max Stress=58.66 MPa

Fig. 12 Stress in Aluminium 6026

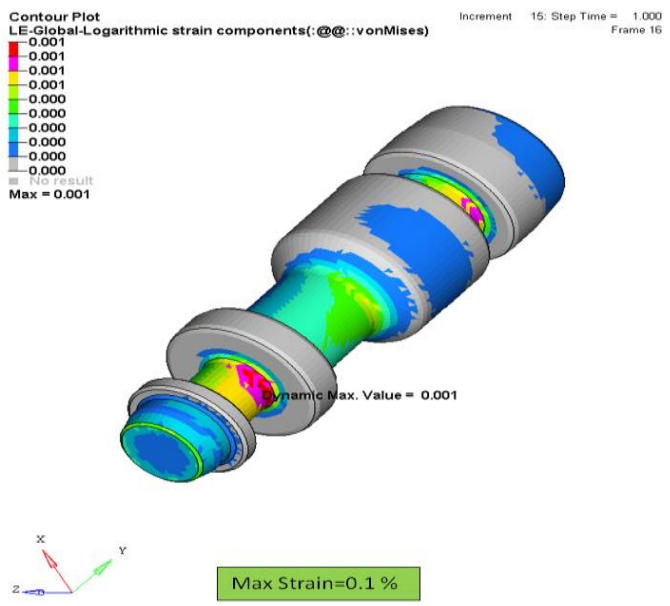

Fig. 13 Strain in Aluminium 6026

From Fig. 8 - 11, it shows the Force vs. Displacement for Aluminium 6026, overall displacement is $0.036 \mathrm{~mm}$ and in $\mathrm{Y}$ axis it is $0.017 \mathrm{~mm}$ whereas displacements in $\mathrm{X}$ and $\mathrm{Z}$ axis are $0.0 \mathrm{~mm}$. Fig. 12 shows that, the stress in Aluminium 6026 is $58.66 \mathrm{MPa}$ which is far below the allowable stress of $360 \mathrm{MPa}$. Fig. 13 shows the strain occurred is $0.1 \%$ where as allowable is $4 \%$. From above figures, the analysis results are expressed in tabular form as follows,

Table 3 Tabular Representation of Analysis Results for Aluminium

\begin{tabular}{|c|c|c|}
\hline Description & Unit & Value \\
\hline Force Applied & $\mathrm{N}$ & 670 \\
\hline Overall Displacements & $\mathrm{mm}$ & 0.036 \\
\hline Displacements in X axis & $\mathrm{mm}$ & 0 \\
\hline Displacements in Y axis & $\mathrm{mm}$ & 0.017 \\
\hline Displacements in Z axis & $\mathrm{mm}$ & 0 \\
\hline Ultimate Stress [9] & $\mathrm{MPa}$ & 360 \\
\hline Maximum Stress observed & $\mathrm{MPa}$ & 58.666 \\
\hline Ultimate Strain [9] & $\%$ & 4 \\
\hline Maximum Strain observed & $\%$ & 0.1 \\
\hline
\end{tabular}


From above Table 3, we get to know that the observed results of stress and strain are well below the allowed stress and strain. The overall displacement occurred in piston is $0.036 \mathrm{~mm}$ and displacement in $\mathrm{X}, \mathrm{Y}$ and $\mathrm{Z}$ axis is negligible. These results depicts that the existing design of aluminium piston is well designed and withstand the forces.

\section{Stress Calculation for Polyphenylene Sulfide $\mathbf{4 0 \%}$ Glass Filled}

The existing model of aluminium is considered for analysis of piston using plastic material properties shown in Table 1 . The analysis gives the following results for Force vs. Displacements in X, Y, Z axis using FORTRON PPS 40\% GF 1140L4 plastic material properties,

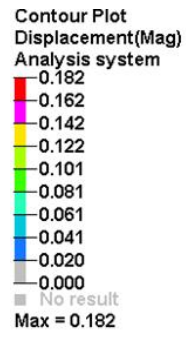

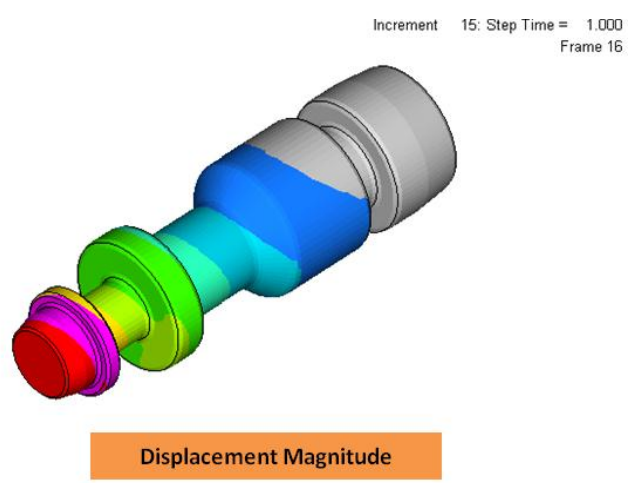

$x^{2} y$

Displacement Magnitude

Fig. 14 Force vs. Displacement Magnitude

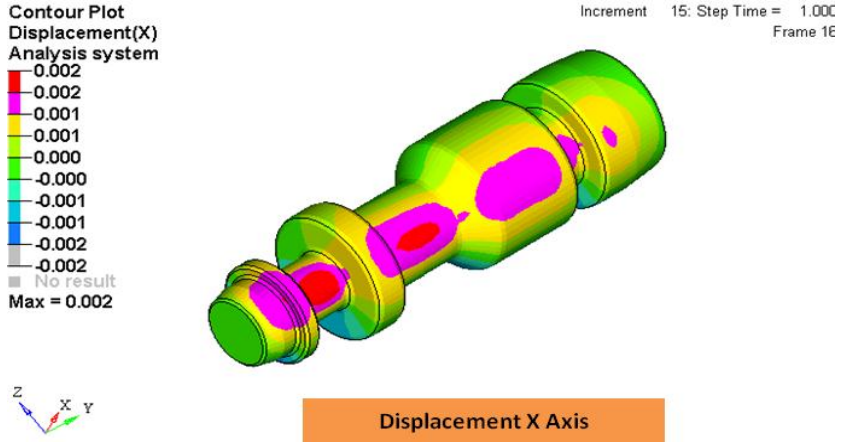

Fig. 15 Force vs. Displacement in X Axis

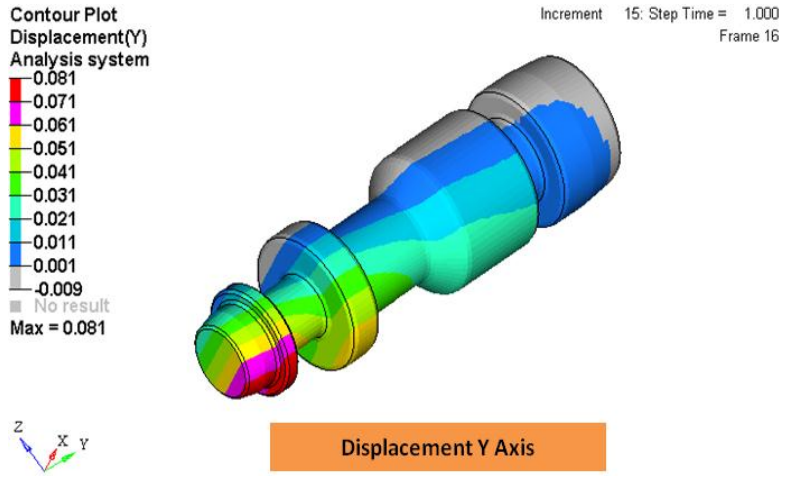

Fig. 16 Force vs. Displacement in Y Axis

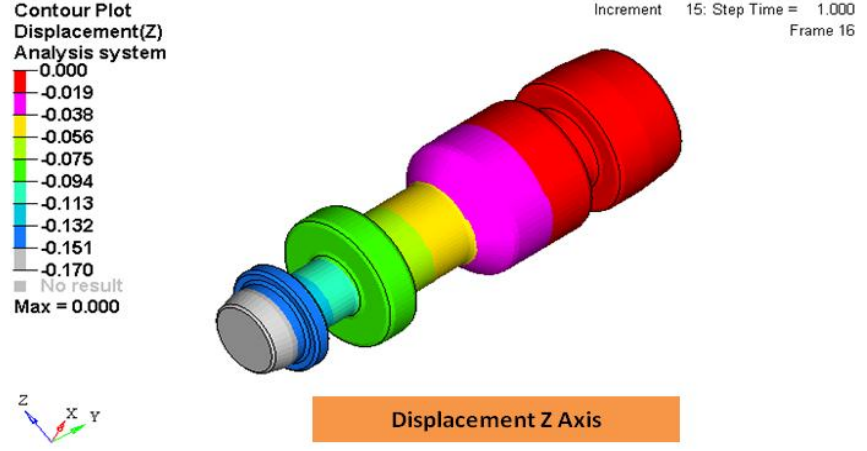

Fig. 17 Force vs. Displacement in Z Axis

For piston using FORTRON PPS 40\% GF 1140L4, the stress- strain plot is as shown below in Fig. 18, 19.

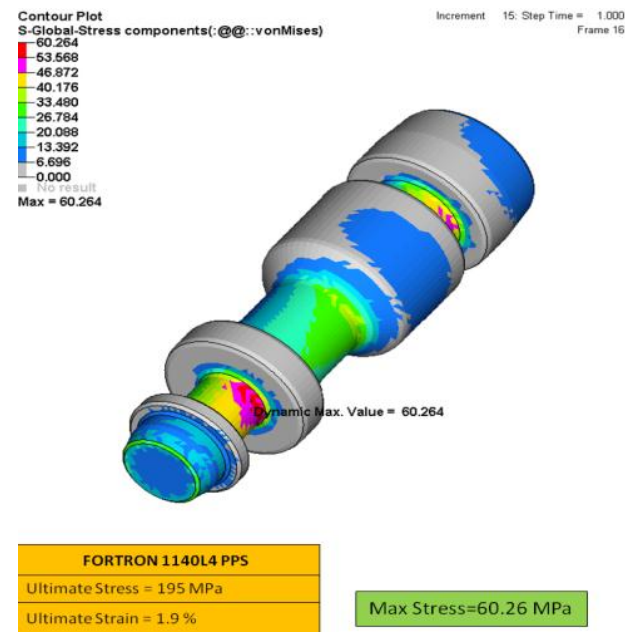

Fig. 18 Stress in PPS 40\% GF

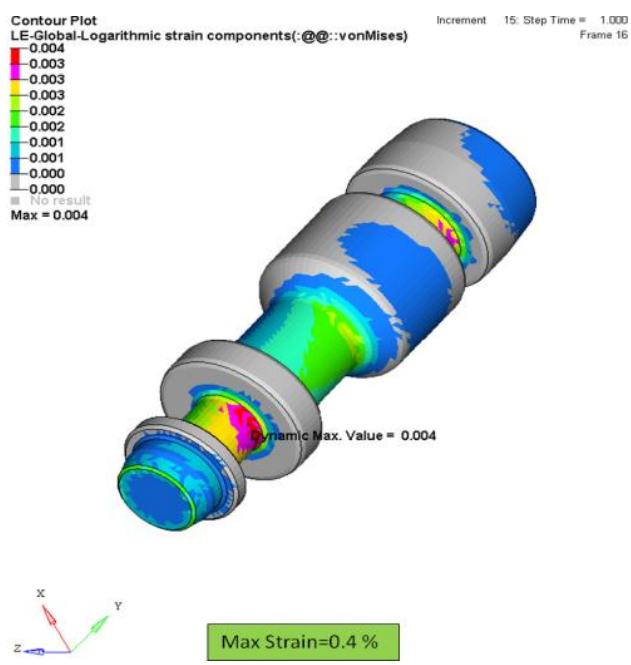

Fig. 19 Strain in PPS 40\% GF

From Figures $14-17$, it shows the Force vs Displacement, overall displacement is $0.182 \mathrm{~mm}$ and displacement in $\mathrm{X}$ axis is $0.002 \mathrm{~mm}$ whereas displacement in $\mathrm{Y}$ axis is $0.081 \mathrm{~mm}$ and $\mathrm{Z}$ axis is $0.0 \mathrm{~mm}$. Fig. 18 shows that, the stress in PPS $40 \%$ GF is 60.26 $\mathrm{MPa}$ which is well below the allowable stress of 195 
MPa. Fig. 19 shows the strain occurred is $0.4 \%$ where as allowable is $1.9 \%$. The analysis results for FORTRON 1140L4 PPS 40\% GF are expressed in tabular form as shown in Table 4 ,

From below Table 4, we get to know that the observed results of stress and strain are well below the allowed stress and strain. The overall displacement occurred in piston is $0.182 \mathrm{~mm}$ and displacement in $\mathrm{X}, \mathrm{Y}$ and $\mathrm{Z}$ axis is negligible. These results represents that the existing design of aluminium piston is well designed and withstand the forces for plastic material also.

Table 4 Tabular Representation of Analysis Results for Polyphenylene Sulfide

\begin{tabular}{|c|c|c|}
\hline Description & Unit & Value \\
\hline Force Applied & $\mathrm{N}$ & 670 \\
\hline Overall Displacements & $\mathrm{mm}$ & 0.182 \\
\hline Displacements in X axis & $\mathrm{mm}$ & 0.002 \\
\hline Displacements in Y axis & $\mathrm{mm}$ & 0.081 \\
\hline Displacements in Z axis & $\mathrm{mm}$ & 0 \\
\hline Ultimate Stress & $\mathrm{MPa}$ & 195 \\
\hline Maximum Stress observed & $\mathrm{MPa}$ & 60.26 \\
\hline Ultimate Strain & $\%$ & 1.9 \\
\hline Maximum Strain observed & $\%$ & 0.4 \\
\hline
\end{tabular}

\section{Weak Regions}

All analysis figures shows that, the slot diameter where " 0 " rings are inserted at two locations are weak for stress and strain as well. As this stress and strain are within the permissible limit i.e. ultimate stress and strain, this does not show the breaking of piston for plastic material.

\section{Causes of Stress Intensity}

Though the stress and strain are occurred at two locations of slot diameter, are very minute and piston can withstand to this. To avoid or reduce this stress and strain, we can use ribs positioned on diameter between this two slots.

\section{Comparison of Plastic Material Results with Existing Material Results}

From analysis figures and result tables, the analyzed data is compiled into one comparison table as below,
Table 5 Comparisons of Aluminium 6026 and Polyphenylene Sulfide 40\% Glass Filled

\begin{tabular}{|c|c|c|c|}
\hline Description & & $\begin{array}{c}\text { Aluminium } \\
6026\end{array}$ & $\begin{array}{c}\text { Polyphenylene } \\
\text { Sulfide }\end{array}$ \\
\cline { 2 - 4 } & Unit & Value & Value \\
\hline Force Applied & $\mathrm{N}$ & 670 & 670 \\
\hline Overall Displacements & $\mathrm{mm}$ & 0.036 & 0.182 \\
\hline Displacements in X axis & $\mathrm{mm}$ & 0 & 0.002 \\
\hline Displacements in Y axis & $\mathrm{mm}$ & 0.017 & 0.081 \\
\hline $\begin{array}{c}\text { Displacements in Z axis } \\
\text { Ultimate Stress }\end{array}$ & $\mathrm{mm}$ & 0 & 0 \\
\hline $\begin{array}{c}\text { Maximum Stress } \\
\text { observed }\end{array}$ & $\mathrm{MPa}$ & 58.666 & 60.26 \\
\hline $\begin{array}{c}\text { Ultimate Strain } \\
\text { Maximum Strain } \\
\text { observed }\end{array}$ & $\%$ & 4 & 1.9 \\
\hline \multicolumn{2}{|c|}{$\%$} & 0.1 & 0.4 \\
\hline
\end{tabular}

From above table we get to know that there is very little deviation in results of Aluminium and Polyphenylene Sulfide $40 \%$ GF. It is evident that the same design can withstand to the forces and can be used for manufacturing the piston in plastic materials. Though, the stresses occurred in piston are negligible, some modifications in the existing piston cad model design is proposed and then it is to be once again analyzed and then the piston will be manufactured in plastic through machine route.

With above procedure, we will get reduction in piston weight, design cost and productivity improvement due to material change of the piston from metal to plastic.

\section{References}

Giri N. K. (2008), Automobile Mechanics, 8th ed., Khanna Publishers, , pp.755 - 760

6,079,961 (United States), May 28, 1999, Piston pump for a vehicle brake system having a plastic piston with a wear resistant cam-striking face, 2000

US 6,457,956 B1 (United States), April 6, 2000, Piston pump, 2002

4,528,895 (United States), Mar. 24, 1983, Piston for cylinder device, 1985

4,309,937 (United States), Oct. 25, 1979, Composite master cylinder pistons, 1982

3,155,014 (Unites States), Jan. 23, 1961, Plastic piston, 1964

2,349,345 (United States), Feb. 11, 1942, Piston, 1944

Celanese (2007), Ticona Engineering Polymers, FORTRON 1140L4 PPS Glass Reinforced.

Wilsons Ltd. (2015), Aluminium Alloy 6026 T9 Rod and Bar 